\title{
USO DO ADESIVO BUTILCIANOACRILATO NO CONTROLE DA HEMORRAGIA APÓS PUNÇÕES HEPÁTICAS EM RATOS
}

\section{USE OF TISSUE ADHESIVE BUTYLCYANOCRYLATE FOR HEMORRHAGE CONTROL AFTER HEPATIC PUNCTURE IN RATS}

\author{
Armando de Capua Junior, TCBC-SP ${ }^{1}$ \\ Mohamed Ibrahim Ali Taha ${ }^{2}$
}

\begin{abstract}
RESUMO: Objetivo: Avaliar o uso do adesivo butilcianoacrilato no controle da hemorragia em punções hepáticas de ratos. Método: Foram utilizados 40 ratos distribuídos em dois grupos, um deles heparinizado e o outro não, submetidos à punção hepática com jelco 14. Metade dos animais de cada grupo foi tratado com o adesivo butilcianoacrilato e a outra metade não recebeu nenhum tipo de tratamento. Resultados: Os animais heparinizados e tratados com adesivo mantiveram os níveis de hematócrito e hemoglobina e uma mínima quantidade de sangue livre na cavidade. Já os animais heparinizados e sem tratamento apresentaram queda significativa dos níveis hematimétricos com moderada quantidade de sangue livre na cavidade $(\mathrm{p}<0.005)$. Conclusão: $O$ adesivo tecidual butilcianoacrilato mostrou ser eficiente como agente hemostático no controle de sangramento de punções hepáticas em ratos heparinizados.
\end{abstract}

Descritores: Biopsia hepática; Adesivo tecidual; Ratos.

\section{INTRODUÇÃO}

Apesar dos grandes progressos da cirurgia nas últimas décadas, o diagnóstico e o seguimento das doenças hepáticas continuam a oferecer dificuldades para a prática médica ${ }^{1,2}$.

A punção hepática, utilizada inicialmente para o diagnóstico e tratamento de abscessos hepáticos, passou a ter finalidades diagnósticas a partir de 1883, quando Paul Ehrlich realizou a primeira biopsia hepática para estudar o conteúdo de glicogênio em fígados diabéticos ${ }^{1}$.

Há seis décadas o método passou a ser mais freqüentemente utilizado com finalidades diagnósticas, tendo sido consolidado a partir da Segunda Guerra Mundial para o estudo de numerosos casos de hepatites virais que acometeram os soldados envolvidos no conflito ${ }^{1}$.

As duas únicas contra-indicações absolutas ao método são o cisto hidático e o hemangioma cavernoso do fígado $^{1}$. Outra contra-indicação para a biopsia hepática são os distúrbios graves de coagulação, medidos pelo alargamento do tempo de protrombina. Alguns autores consideram ainda indispensável para avaliação da coagulação a contagem de plaquetas, cujo limite de segurança estaria em torno de $80.000^{1-7}$.

A hemorragia representa cerca de metade das complicações, sendo a principal causa de mortalidade. Estudos realizados relatam que as taxas de hemorragias com necessidade de reposição volêmica atingiram $0,2 \%$ a $0,25 \%$ das biopsias realizadas, e $6 \%$ a $25 \%$ destes pacientes necessitaram de laparotomia ${ }^{2-7}$.

A peritonite biliar representa cerca de $15 \%$ das complicações. A disseminação tumoral pelo trajeto da punção é uma complicação rara, porém descrita na literatura. Alguns autores recomendam que a biopsia só deva ser realizada em pacientes não candidatos à ressecção cirúrgica ${ }^{2,3}$.

1. Professor Titular e Diretor do Departamento de Cirurgia da Faculdade de Ciências Médicas da Santa Casa de São Paulo.

2. Residente do terceiro ano de Cirurgia do Aparelho Digestivo da Faculdade de Ciências Médicas da Santa Casa de São Paulo.

Recebido em 02/05/2000.

Aceito para publicação em 03/01/2002.

Trabalho realizado no centro de cirurgia experimental da Faculdade de Ciências Médicas da Santa Casa de São Paulo 
Os autores têm como objetivo avaliar a aplicabilidade do adesivo tecidual butilcianoacrilato em punções hepáticas de ratos submetidos ou não à heparinização, visando ao controle de hemorragia.

\section{MÉTODO}

Foram utilizados 40 ratos da raça Wistar machos, adultos, com peso entre $250 \mathrm{~g}$ e $350 \mathrm{~g}$, provenientes do Biotério Central da Santa Casa de São Paulo. Os animais foram distribuídos em dois grupos, sendo um deles heparinizado e o outro não.

A heparinização foi realizada com heparina sódica na dose de $1 \mathrm{ml} / \mathrm{kg}$ de peso por via endovenosa. Os animais foram mantidos em jejum alimentar de 12 horas com água ad libitum.

A anestesia foi realizada com cloridrato de ketamina, na dose de $40 \mathrm{mg} / \mathrm{kg}$ de peso associado a xylazina $10 \mathrm{mg} /$ $\mathrm{kg}$ de peso, intramuscular.

O acesso à cavidade abdominal foi efetuado por pneumoperitônio na região da cicatriz umbilical com trocarte de $5 \mathrm{~mm}$, com pressão de $\mathrm{CO}_{2}$ de $4 \mathrm{mmHg}$ seguida de locação de óptica de $4 \mathrm{~mm}$, com inventário da cavidade, visibilização do fígado e suas estruturas. Identificado o lobo hepático direito, foi produzida punção na região central com jelco número 14 .

Dos animais do grupo controle, dez não foram submetidos a nenhum tipo de tratamento. O restante foi submetido à aplicação do adesivo butilcianoacrilato, através do jelco (Figura 1). O grupo com heparinização foi distribuído da mesma forma que o grupo controle, e submetido aos mesmos procedimentos. Os animais foram avaliados sob o ponto de vista clínico e laboratorial. O tempo de avaliação foi de 24 horas, com dosagem de hemoblobina $(\mathrm{Hb})$ e hematócrito (Ht), e os sobreviventes, mortos com $0,5 \mathrm{ml}$ de $\mathrm{KCl}$ intracardíaco.

A análise estatística dos resultados foi feita pelo método t de Student para hemoglobina e quantidade de sangue na cavidade e pelo método de Mann-Whitney para hematócrito.

\section{RESULTADOS} Tabela 1

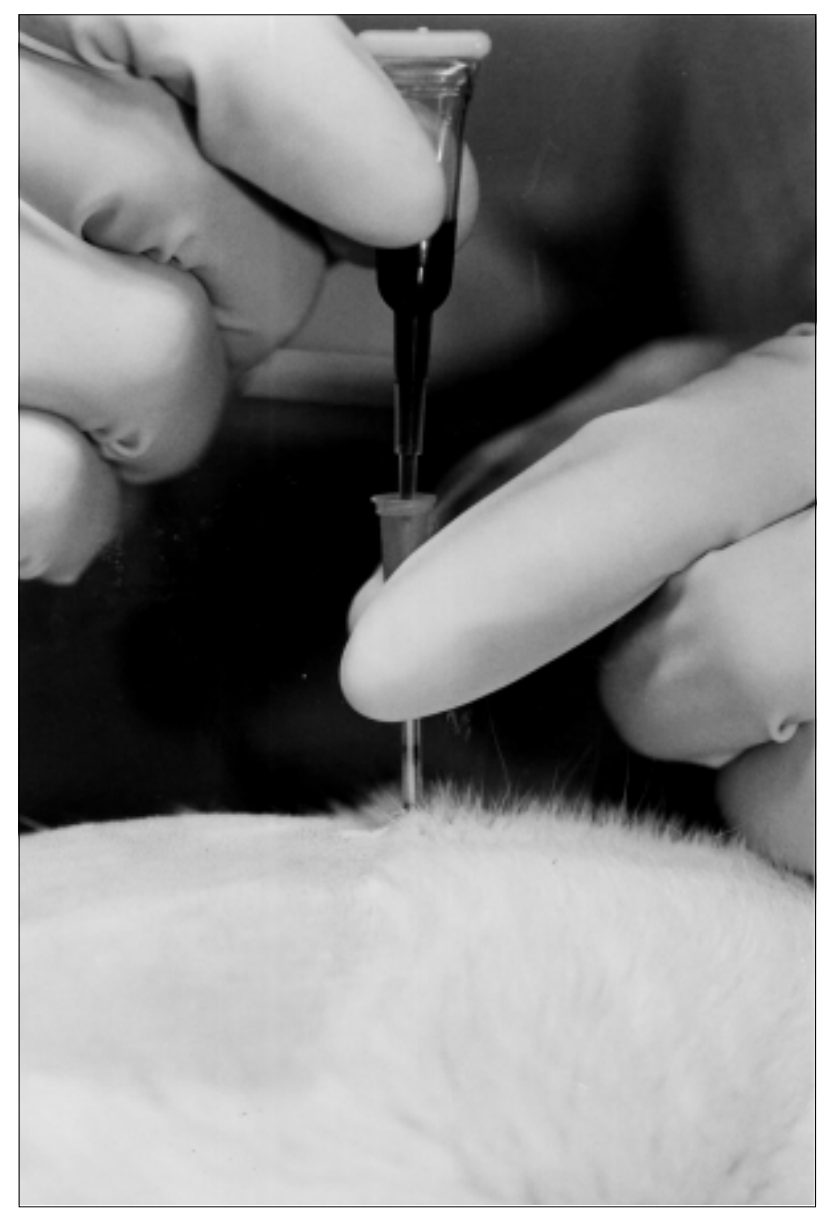

Figura 1 - Aplicação do adesivo butilcionacrilato sob pressão manual através do jelco 14.

\section{DISCUSSÃO}

O grande interesse despertado pela biopsia hepática ocorre devido à sua importância no diagnóstico e avaliação prognóstica das mais variadas doenças que acometem o fígado ${ }^{1-3}$.

Trata-se de um procedimento relativamente simples de ser executado nas mãos de profissionais habilitados. Porém, não está isento de complicações ${ }^{1,6}$.

Tabela 1

Análise das médias de hemoglobina (Hb), hematócrito (Ht), e sangue livre na cavidade, de ratos heparinizados e não heparinizados submetidos à punção hepática via laparoscópica tratados com adesivo butilcianoacrilato e de animais sem tratamento

\begin{tabular}{l|c|c|c|c}
\hline \multirow{2}{*}{} & \multicolumn{2}{|c|}{ Não heparinizados } & \multicolumn{2}{c}{ Heparinizados } \\
\cline { 2 - 5 } & Sem tratamento & Adesivo & Sem tratamento & Adesivo \\
\hline $\mathrm{Hb} \mathrm{g} / \mathrm{dl}$ & 14,16 & $14,43(\mathrm{NS})$ & 9,88 & $13,94(\mathrm{~S})$ \\
$\mathrm{Ht}(\%)$ & 43,96 & $44,51(\mathrm{NS})$ & 30,17 & $43,96(\mathrm{~S})$ \\
Sangue livre (ml) & 0,21 & $0,16(\mathrm{NS})$ & 0,87 & $0,14(\mathrm{~S})$ \\
\hline
\end{tabular}

NS: não significante;

S: significante. 
Estudos avaliaram as taxas de complicações após biopsias hepáticas das mais diversas doenças, sendo as principais: hemorragia $(0,25 \%)$, peritonite biliar $(0,18 \%)$, disseminação tumoral e mortalidade $(0,086 \%)$. Porém, nos pacientes cirróticos que apresentam distúrbios de coagulação, estes valores chegam a até $15 \%$, tornando-se muitas vezes inviável a realização do procedimento ${ }^{3,4,6,7}$.

A relação risco-benefício deve ser considerada na indicação da biopsia hepática, já que nos casos em que a biopsia é mandatória para o diagnóstico e a terapêutica, as contra-indicações tornam-se relativas devendo ser contornadas segundo critério e experiência da equipe médica ${ }^{1}$.

A utilização do adesivo tecidual após a punção hepática teve por objetivo diminuir a presença de complicações e tornar possível a realização do procedimento na presença de distúrbios de coagulação ${ }^{8,9}$.

$\mathrm{Na}$ vigência de neoplasias a complicação temível é a disseminação tumoral, tanto para a cavidade peritoneal como pelo trajeto da agulha ${ }^{3}$. $\mathrm{O}$ adesivo tecidual agindo como um tampão no local da biopsia impediria a propagação das células neoplásicas.

O estudo teve o rato como animal de escolha por ser fácil sua aquisição e adaptação em serviço de cirurgia experimental, além de ser freqüentemente utilizado em procedimentos da mesma natureza, como BiondoSimões et al. ${ }^{10}$, que utilizaram ratos no estudo do tratamento de lesões hepáticas.

A via laparoscópica permitiu um bom acesso ao fígado, possibilitando a escolha do local da punção e seu controle hemostático.

O curto espaço de tempo a que os animais foram submetidos ao procedimento não provocou alterações na mecânica ventilatória, o que nos permitiu manter os animais sob ventilação espontânea com boa visão da cavidade abdominal. A pressão de $4 \mathrm{mmHg}$ do pneumoperitônio permitiu uma boa visibilização do fígado, não promovendo alterações hemodinâmicas, como nos estudos de Ishitani et al. ${ }^{11}$.

O jelco $14 \mathrm{G}$ mostrou-se eficiente na realização de punções hepáticas e permitiu o encaixe do refil adesivo com acesso direto ao local de sangramento.

Um dispositivo semelhante ao mecanismo do jelco, que envolvesse a agulha de biopsia, permitiria a realização do procedimento com posterior aplicação do adesivo, tornando o modelo proposto adequado à prática clínica.

A hemoglobina e o hematócrito foram os exames de escolha para avaliação da eficácia do método, sendo estes os parâmetros utilizados por Salvino et $a l^{12}$.

A escolha da substância adesiva baseou-se na sua composição, mecanismo de ação e efeitos colaterais ${ }^{13-17}$.

$\mathrm{O}$ adesivo butilcianoacrilato apresenta potente efeito hemostático, ligando-se fortemente à superfície de contato, não necessitando de solução polimerizante e, portanto, de fácil manuseio. Tais características foram fundamentais na escolha desta cola em nosso estudo. Soehendra et al. ${ }^{18}$ e Willians e Westaby ${ }^{19}$ em estudos clínicos e experimentais obtiveram sucesso com o uso de butilcianoacrilato na hemostasia de varizes gástricas e esofágicas sangrantes.
$\mathrm{O}$ adesivo utilizado butilcianoacrilato promoveu hemostasia eficaz e imediata, com formações de polímeros sólidos e aderentes ao ferimento (Figura 2).

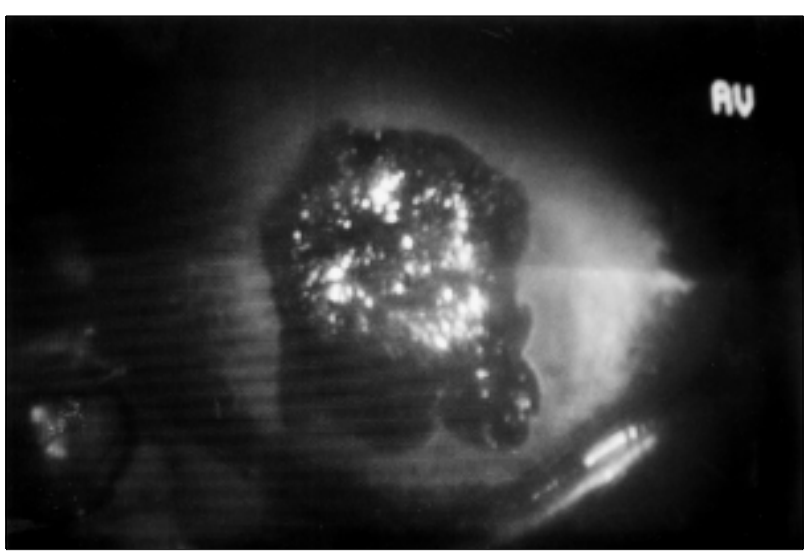

Figura 2 - Presença de hemostasia imediata após punção hepática seguido de uso do adesivo butilcianacrilato com polimerização ao redor da lesão, em rato heparinizado.

Na avaliação pós-operatória não foram observados óbitos em nenhum dos grupos.

A variação das taxas de hemoglobina e hematócrito não demonstrou diferença estatiscamente significante nos ratos não heparinizados tratados ou não com adesivo, comprovando que na ausência de distúrbios de coagulação o butilcianoacrilato não mostrou vantagens.

Os animais heparinizados e tratados com o adesivo butilcianoacrilato apresentaram mínima quantidade de sangue na cavidade abdominal e mantiveram os valores de hemoglobina e hematócrito dentro da normalidade. Porém, aqueles heparinizados e sem tratamento apresentaram moderada quantidade de sangue na cavidade e queda significativa nas taxas de hemoglobina e hematócrito (Tabela 1).

No grupo de animais no qual foi criada uma desordem de coagulação, através da heparinização, o adesivo mostrou-se de fundamental importância no controle do sangramento, demonstrado pela manutenção dos valores hematimétricos e ausência de sangramento abdominal.

A importância clínica destes resultados deve-se ao fato de tornar possível a realização da biopsia hepática em pacientes cirróticos e plaquetopênicos, que em vigência de seus distúrbios de coagulação tem contra-indicação à realização do procedimento $1,2,3,4,6,7,9$.

O estudo realizado comprovou a eficiência do adesivo butilcianoacrilato no controle de sangramento de punções hepáticas, devendo-se ressaltar a importância da criação de um dispositivo capaz de adequar o adesivo nas agulhas de biopsia hepática.

$\mathrm{O}$ adesivo tecidual butilcianoacrilato mostrou ser eficiente como agente hemostático no controle de sangramento de punções hepáticas em ratos heparinizados. 


\begin{abstract}
Background: The objective of this study was to assess the effectiveness of tissue adhesive butylcyanocrylate in liver biopsy. Method: Forty rats were divided in two groups: one group included heparin-injected rats; the second group was not injected with heparin. Liver punction was performed with a 14-gauge needle. Half of the animals in each group was treated with tissue adhesive butylcyanocrylate and the other half had no treatment. Results: The heparin-injected rats treated with adhesive kept their initial hemoglobin and hematocrit levels and had minimal amount of blood in the abdominal cavity. On the other hand, non treated heparin-injected rats presented a significant drop in hemoglobin and hematocrit levels and had a moderate volume of blood in the cavity. Conclusions: The tissue adhesive butylcyanocrylate showed be efficient as a hemostatic agent.
\end{abstract}

Key Words: Liver biopsy; Tissue adhesive; Rats.

\title{
REFERÊNCIAS
}

1. Gayotto LCC. Biópsia Hepática. In: Mincis M. Gastroenterologia e Hepatologia - Diagnóstico e Tratamento. Rio de Janeiro, Lemos, 1994, p.183-201.

2. Losowsky MS. Liver Biopsy. In: Blumgart, L.H..Surgery of the liver and biliary tract, 1994. v.23,p.353-62.

3. Chuah SY. Liver Biopsy - Past, Present and Future. Singapore Med J., 1996; 37: 86-90.

4. Ewe K. Bleeding After Liver Biopsy Does Not Correlate with Indices of Peripheral Coagulation. Digestive Diseases and Sciences, 1981; 26: 388-93.

5. Jacobs WH, Goldberg SB. Statement on Outpatient Percutaneous Liver Biopsy. Digestive Diseases and Sciences, 1989; 34: 322-3.

6. Fornari F, Civardi G, Cavanna L et al. Complications of Ultrasonically Guided Fine-Needle Abdominal Biopsy. Scand J. Gastroenterol, 1989; 24: 949-55.

7. Sada PN, Ramakrishna B, Thomas $\mathrm{CP}$ et al. Transjugular liver biopsy: a comparison of aspiration and trucut techniques. Liver, 1997; 17: 257-9.

8. Paulista P, Arnoni A, Souza L et al. Emprego da Cola Biológica no Tratamento Cirúrgico da Dissecção Aórtica: Relato de Três Casos. Arq. Bras. Cardiol., 1988; 50:269-73.

9. Sakon M, Monden M, Gotoh M et al. Use of Microcrystalline Collagen Powder and Fibrinogen Tissue Adhesive for Hemostasis and Prevention of Rebleeding in Patients with Hepatocellular Carcinoma Associated with Cirrhosis of the Liver. Surg, Gynecol Obstet,1989; 168: 453-4.

10. Biondo-Simões MLP, Tenius FP, Cavazana WC et al. Uso de Adesivo em Trauma Hepático: Estudo Experimental em Ratos..Acta Cir. Bras, 1993; 8: 24-7.

11. Ishitani M, McGahren E, Sibley D et al. Laparoscopically Applied Fibrin Glue in Experimental Liver Trauma. J. Ped. Surg., 1989; 24: 867-71.

12. Salvino C, Esposito T, Smith D et al. Laparoscopic Injection of Fibrin Glue to Arrest Intraparenchymal Abdominal Hemorrhage: An Experimental Study. J. Trauma, 1993; 35: 762-6.

13. Albes J, Krettek C, Hausen B et al. Biophysical Properties of the Gelatin-Resorcin-Formaldehyde / Glutaraldehyde Adhesive. Ann. Thorac. Surg, 1993; 56: 910-5.

14. Hjortrup A, Nordkild P, Christensen T et al. Rectal Anastomosis with Application of Luminal Fibrin Adhesive in Rectum of Dogs: An Experimental Study. Dis Colon Rectum,1989; 32: 422-5.
15. Almeida C, Nina L, Mello R. Cola Biológica Autógena. Original Article, 1990; 115-118.

16. Kulkarni RK, Hanks GA, Pani KC et al. The in Vivo Metabolic Degradation of Poly (methyl Cianocrylate) Via Thiocyanate. J. Biomed. Mater. Res.,1967; 1: 11-6.

17. Morandini W, Ortiz V. Adesivos Biológicos em Cirurgia. Acta Cir. Bras.,1992; 7: 80-3.

18. Soehendra N, Grimm H, Nam VC et al. N-Butyl-2-Cyanocrylate: A Supplement to Endoscopic Sclerotherapy. Endoscopy, 1987; 19: 221-4.

19. Williams S, Westaby D. Recent Advances in the Endoscopic Management of Variceal Bleeding. GUT, 1996; 36: 647-8.

Endereço para correspondência:

Dr. Armando de Capua Júnior

Av. Comendador Adibo Ares, 944

05613-0001 - São Paulo-SP 